\title{
WAVE OVERTOPPING WITH A CHANGING STEEP SANDY FORESHORE, CONVENTIONAL AND NUMERICAL ANALYSIS OF RESULTS
}

\author{
Jentsje van der Meer, IHE Delft and Van der Meer Consulting, jm@vandermeerconsulting.nl; \\ Rizki Akbar, Former student IHE Delft, a.muscarina.itb@gmail.com; \\ Ryard Mukhdiar, Former student IHE Delft, ryard.ryd@gmail.com; \\ Riccardo Briganti, University of Nottingham, riccardo.briganti@nottingham.ac.uk; \\ Rosaria Ester Musumeci, University of Catania, rmusume@dica.unict.it; \\ Alessandro Romano, University La Sapienza, alessandro.romano@uniroma1.it; \\ Tomohiro Suzuki, Flanders Hydraulics Research, tomohiro.suzuki@mow.vlaanderen.be; \\ Corrado Altomare, University of Ghent, corrado.altomare@ugent.be
}

\section{THE ICODEP PROJECT}

Large scale tests were performed in the large scale facility GWK at Hannover, Germany, within the HYDRALAB+ project ICODEP: Impact of Changing fOreshore on flood DEfence Performance. The test setup consisted of a relatively steep 1:15 sandy beach profile in front of a battered seawall with 10:1 slope (almost vertical). Two storms were generated, S1 and S2 with for each storm a specific combined surge and tide profile with varying wave conditions (sea states) depending on water level. These two types of storms have been modelled in varying order, giving three types of storm clusters (C1, C2, and C3). After each sea state the foreshore profile was measured and during each sea state wave conditions as well as wave overtopping have been measured. The changing foreshore showed a breaker bar formation as well as scour or accretion directly in front of the battered wall, depending on water level.

\section{OBJECTIVE OF THE PAPER}

The abstract by Briganti et al. in this conference is focused on the results of the measurements, such as changes of the beach (erosion and bar formation, scour) and the relation with the measured overtopping, but without analysis of overtopping itself. This paper will focus on validating the EurOtop (2016) guidelines on wave overtopping (the conventional analysis) and will discuss the performance of XBeach to simulate the bar and scour behaviour of the sandy foreshore, as well as calculating the overtopping discharge.

WAVE OVERTOPPING ACCORDING TO EUROTOP EurOtop (2016) describes impulsive wave overtopping on a battered $10: 1$ wall by equations 7.7 and 7.8 , which is then multiplied by a factor of 1.3 to cope with the effect of not being a vertical wall (equation 7.11).

$$
\begin{aligned}
& \frac{q}{\sqrt{g H_{m 0}^{3}}}=0.011\left(\frac{H_{m 0}}{h s_{m-1,0}}\right)^{0.5} \exp \left(-2.2 \frac{R_{c}}{H_{m 0}}\right) \\
& \frac{q}{\sqrt{g H_{m 0}^{3}}}=0.0014\left(\frac{H_{m 0}}{h s_{m-1,0}}\right)^{0.5}\left(\frac{R_{c}}{H_{m 0}}\right)^{-3}
\end{aligned}
$$

Eq. 7.7 is valid for $0<R d H_{m o}<1.35$ and Eq. 7.8 for $R_{c} / H_{m o} \geq 1.35$. In the equations $q=$ overtopping discharge $\left(\mathrm{m}^{3} / \mathrm{s}\right.$ per $\left.\mathrm{m}\right) ; \mathrm{g}=$ acceleration of gravity $\left(\mathrm{m}^{2} / \mathrm{s}\right)$; significant wave height $(\mathrm{m}) ; \mathrm{h}=$ water depth $(\mathrm{m}) ; \mathrm{s}_{\mathrm{m}-1,0}=$ notional wave steepness (-) with spectral period $T_{m-1,0}$, deep water steepness with $\mathrm{H}_{\mathrm{mo}}$ at the toe of the structure; and $R_{c}=$ crest freeboard $(m)$.

$\begin{array}{ll}\text { 10:1 battered wall: } & \mathrm{q}_{10: 1 \text { batter }}=\mathrm{q}_{\text {vertical }} \times 1.3 \\ \text { 5:1 battered wall: } & \mathrm{q}_{5: 1 \text { batter }}=\mathrm{q}_{\text {vertical }} \times 1.9\end{array}$

These equations need the incident wave conditions at the toe of the structure. These are of course changing due to erosion of the foreshore, see Fig. 1.

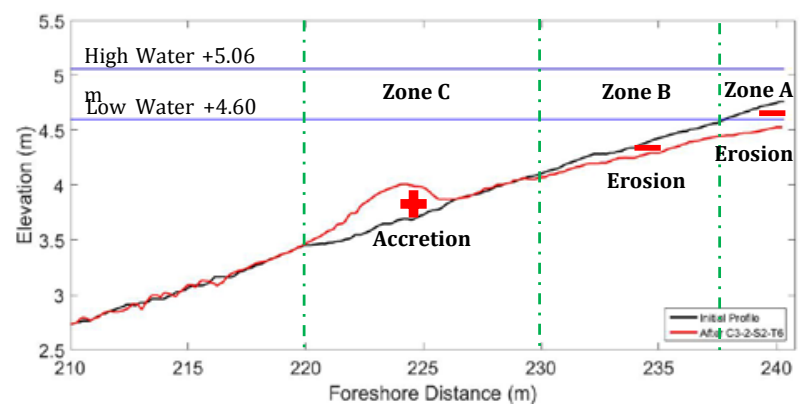

Figure 1 - Scour, erosion and bar formation at the beach.

In order to determine these conditions, the average foreshore slope between chainage $230 \mathrm{~m}$ and $240 \mathrm{~m}$ was measured after each test step and the wave conditions were calculated by the graphical method given in section 2.3.2 of EurOtop (2016). Comparison with measured results showed a fair agreement, see Figure 2. All differences are within a factor of 2 , which is quite good for wave overtopping.

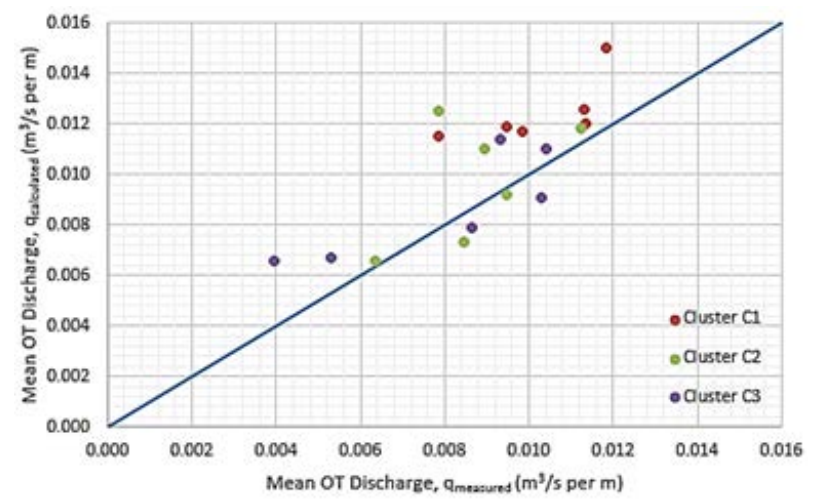

Figure 2. Direct comparison of $\mathrm{q}_{\text {measured }}$ and $\mathrm{q}_{\text {calculated }}$ for all storm clusters. 
Taking into account the erosion of the foreshore and the changing foreshore slope and depth, leads to overtopping discharges that are 2-3 times larger than just taking the initial (fixed) 1:15 foreshore slope, which means that it is important to take into account foreshore changes during storm and/or storm clusters. In the analysis above the measured foreshore profiles were used to calculate the incident wave height at the toe of the structure. In reality and in forecasting one does not have the changed bathymetry of the foreshore and therefore it is not possible to predict the wave overtopping. Only by hindsight one gets the relationship as in Figure 2. A possible prediction method also needs a prediction of foreshore changes. This has been described in the next section.

\section{SIMULATIONS BY XBEACH}

The non-hydrostatic (wave resolving) version of XBeach (Smit et al. 2010) was used to simulate morphological changes as well as wave overtopping. XBeach was simulating very well near structure scour (see Fig. 3) as well as accretion and also the erosion for the first $10 \mathrm{~m}$. But XBeach was not capable to simulate the strong bar formation that was found during testing, see Fig. 3. Detailed results will be given at the conference.

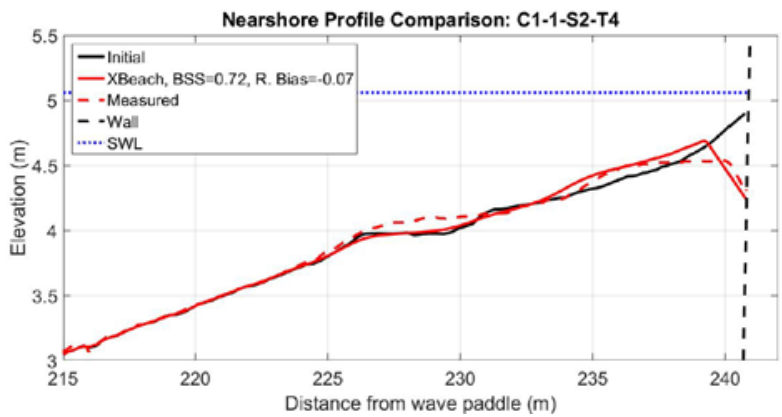

Figure 2 - Morphogical changes measured and simulated by XBeach.

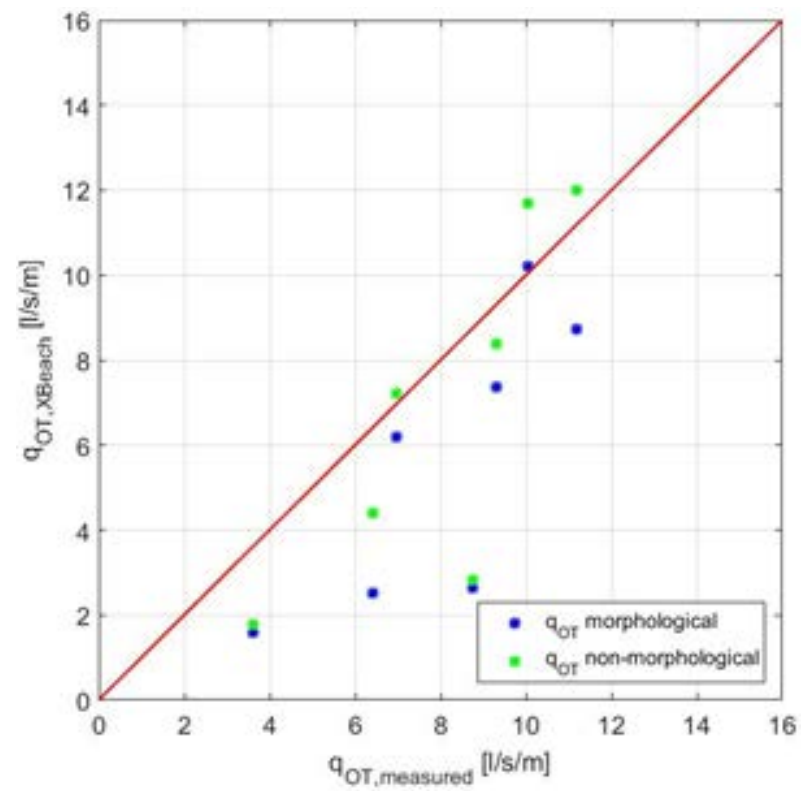

Figure 4. Mean wave overtopping discharge for cases of high SWL: model vs measurements; XBeach calculations.
The non-hydrostatic XBeach is also able to calculate wave overtopping in the time domain, resulting finally in the mean overtopping discharge. Specifically for the very steep battered wall, the results were in good agreement with measured overtopping discharges for the highest water level and for large overtopping, see Figure 4. The differences were always within a factor of 3. Differences were significant for the low water level and very small overtopping discharges.

\section{REFERENCES}

EurOtop (2016). Manual on wave overtopping of sea defences and related structures. An overtopping manual largely based on European research, but for worldwide application. www.overtopping-manual.com.

Smit, Stelling, Roelvink, Van Thiel de Vries, McCall, , Van Dongeren, Zwinkels, and Jacobs (2010). XBeach Non-hydrostatic model: validation, verification and model description. Report, Delft University of Technology, Delft, The Netherlands. 